environment, say clear-air turbulence or something like that, it may be desirable to warn other aircraft of the situation. Since the pressure environment itself may be rapidly changing, the only way you could pinpoint the situation might be by giving the navigational position and the altitude relative to sea-level, which is not going to change rapidly with the pressure or environment.

\title{
ADMIRAL OF THE FLEET SIR HENRY OLIVER
}

Admiral of the Fleet Sir Henry Oliver, G.c.B., к.c.m.G., M.v.o., an Honorary Member of this Institute, who died on 15 October 1965 in his 101 st year, was an outstanding seaman and famous for his many achievements in an active naval career spanning half a century. While his tenure as Chief of the War Staff at the Admiralty from 1914 to 1918 may have been his most valuable service to the nation, his most lasting contribution to the Royal Navy was the foundation of a properly constituted Navigation School which has lasted to this day.

Oliver was trained in sail and spent five years in the Surveying Service before joining the Navigation branch. He learnt his navigation in the days before gyro compasses, echo sounders and radio direction finding. He found the navigation training of officers a haphazard business with little fornal training, few common standards and a expertize picked up largely by self-tuition on the job at sea.

His qualities as a navigator were quickly recognized and he made his name as Navigator of the Flagship when he took the Channel Fleet from the North of Ireland through the Irish Sea to anchorage in St. Mary's Scilly Islands in thick fog during the 1901 naval manœuvres.

His proposals for reorganizing navigation training were accepted by Admiral Fisher and in 1903 he was promoted Captain and appointed in charge of the Navigation Training Ship, H.M.S. Mercury. Two years later the school was established ashore in Portsmouth with two sea-going tenders for practical training. It is from one of these, H.M.S. Dryad, that the Navigation School takes its name.

Oliver commanded the school until 1907, setting it firmly on its path. During this time he helped Lord Kelvin to develop sounding machines and he maintained a keen interest in the school's activities until his death. 